\title{
Punching and Local Damages of Fiber and FRP Reinforced Concrete under Low-Velocity Impact Load
}

\author{
Kyung-Hwan Min \\ Rail Research Institute, Chungnam National University, Daejeon, South Korea \\ Email: alskh@cnu.ac.kr
}

How to cite this paper: Min, K.-H. (2018) Punching and Local Damages of Fiber and FRP Reinforced Concrete under Low-Velocity Impact Load. Open Journal of Civil Engineering, 8, 64-81.

https://doi.org/10.4236/ojce.2018.81006

Received: February 1, 2018

Accepted: March 17, 2018

Published: March 20, 2018

Copyright $\odot 2018$ by author and Scientific Research Publishing Inc. This work is licensed under the Creative Commons Attribution International License (CC BY 4.0).

http://creativecommons.org/licenses/by/4.0/

\section{cc (i) Open Access}

\begin{abstract}
In recent years, the development and application of high performance fiber reinforced concrete or cementitious composites are increasing due to their high ductility and energy absorption characteristics. However, it is difficult to obtain the required properties of the FRCC by simply adding fiber to the concrete matrix. Many researchers are paying attention to fiber reinforced polymers (FRP) for the reinforcement of construction structures because of their significant advantages over high strain rates. However, the actual FRP products are skill-dependent, and the quality may not be uniform. Therefore, in this study, two-way punching tests were carried out to evaluate the performances of FRP strengthened and steel and polyvinyl alcohol (PVA) fiber reinforced concrete specimens for impact and static loads. The FRP reinforced normal concrete (NC), steel fiber reinforced concrete (SFRC), and PVA FRCC specimens showed twice the amount of enhanced dissipated energy (total energy) under impact loadings than the non-retrofitted specimens. In the low-velocity impact test of the two-way NC specimens strengthened by FRPs, the total dissipated energy increased by 4 to 5 times greater than the plain NC series. For the two-way specimens, the total energy increased by $217 \%$ between the non-retrofitted SFRC and NC specimens. The total dissipated energy of the CFRP retrofitted SFRC was twice greater than that of the plain SFRC series. The PVA FRCC specimens showed 4 times greater dissipated energy than for the energy of the plain NC specimens. For the penetration of two-way specimens with fibers, the Hughes formula considering the tensile strength of concrete was a better predictor than other empirical formulae.
\end{abstract}

\section{Keywords}

Fiber Reinforced Concrete, Steel Fiber, Polyvinyl Alcohol (PVA) Fiber, Fiber Reinforced Polymer (FRP), Low-Velocity Impact Load, Punching, Penetration 
Depth

\section{Introduction}

The addition of fiber reinforcement is one of the most effective methods for enhancing the performance of concrete [1] [2] [3]. Conventional fiber reinforced concrete has been developed since the 1960s. In recent years, the development and application of high performance fiber reinforced cementitious composites (HPFRCC) are increasing due to their high ductility and energy absorption characteristics [4] [5] [6] [7]. However, it is difficult to obtain the required properties of the FRCC by simply adding fiber to the concrete matrix. In particular, to overcome the main weaknesses of conventional concrete (low tensile strength and ductility), higher volume fraction of fibers and smaller size of aggregates are applied to fiber-reinforced composites during mixing process. In addition, as shown in Figure 1, more than two types of fibers are used simultaneously to control micro cracks and macro cracks. This requires complex compounding processes, which can lead to entanglement or lack of uniform distribution of fibers in the matrices.

Many researchers are paying attention to fiber reinforced polymers (FRP) for the reinforcement of construction structures because of their significant advantages over high strain rates [8] [9] [10] [11]. However, the actual FRP products are skill-dependent, and the quality may not be uniform. Apart from cost, the most essential problem in the FRP system is the "bond" between the FRP and concrete. The ACI 440 assumes only two failure modes for design calculations: compressive failure of the concrete and failure of the FRP strengthening system [12] [13]. Typical failure modes of FRP-plates or sheet reinforced RC beams are classified as FRP rupture, crushing of compressive concrete, shear failure, concrete cover separation, plate-end interfacial debonding, intermediate flexural crack-induced interfacial debonding, and intermediate flexural shear crack-induced interfacial debonding [14]. Also, almost all failure modes show a brittle manner. Therefore, in this study, two-way punching tests were carried out
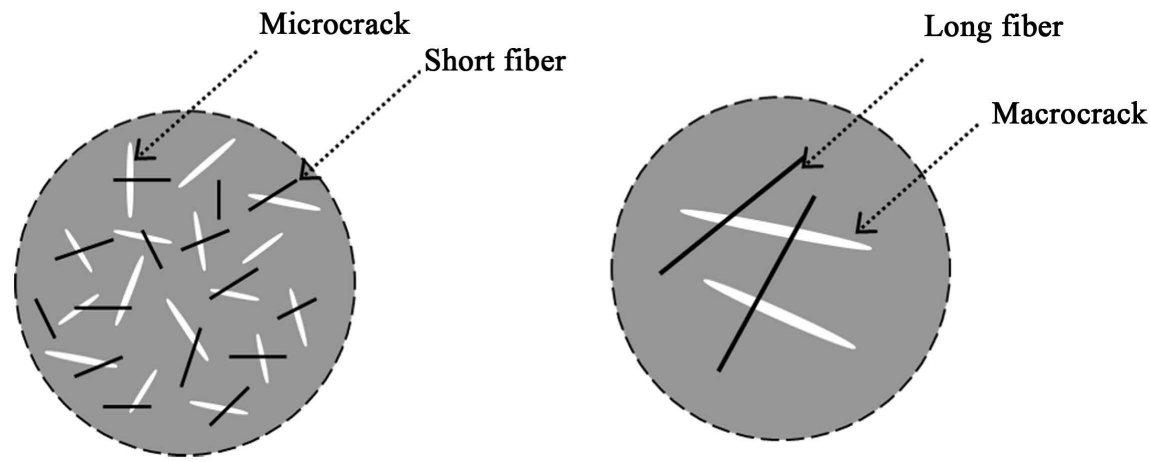

Figure 1. Effects on fibers on cracking. 
to evaluate the performances of FRP strengthened and steel and synthetic fiber reinforced concrete specimens for impact and static loads.

\section{Experimental Programs}

\subsection{Test Variables}

The test variables in this study are summarized in Table 1 . Three concrete matrices (normal concrete (NC), steel fiber reinforced concrete (SFRC), and hybrid PVA fiber reinforced cementitious composite (FRCC), were used to fabricate the test specimens. Table 2 shows the mix proportions of the concrete matrix. Ordinary Portland cement was used for a $40 \mathrm{MPa}$ design strength NC. For the NC's mixture, 50\% water to cement ratio (W/C) was applied. Aggregates were crushed gravels with a maximum size of $20 \mathrm{~mm}$, and sea sand. In order to achieve workability, a liquid type polycarboxylate super-plasticizer was injected. A $0.75 \%$ volume fraction of long steel fiber (30 $\mathrm{mm}$ end hooked) was applied into the normal concrete mixture for the steel fiber reinforced concrete (SFRC).

Table 3 presents the mix proportions of PVA FRCC [6] [7] [15] [16]. In the PVA FRCC mixture, there is no coarse aggregate, but 100 to $120 \mu \mathrm{m}$ silica sand only used for an aggregate. Properties of steel and PVA fiber are summarized in Table 4 and shapes of fiber are shown in Figure 2. The total volume of fraction of the PVA fiber is $2 \%$. In actual mixtures, two different PVA fibers were used, simultaneously, and a ratio of two fibers was selected from compressive and flexural strength tests [6] [7] [16]. From the mechanical tests, as summarized in Table $5,1.6 \%$ and $0.4 \%$ for short (REC15) and long (RF4000) selected, respectively.

Table 1. Variables of material test.

\begin{tabular}{ccc}
\hline Variable & Details & Notation \\
\hline \multirow{2}{*}{ Concrete } & Normal concrete (NC) & N \\
& Steel fiber reinforced concrete (SFRC) & S \\
& Hybrid PVA fiber reinforced cementitious composite (FRCC) & P \\
FRP strengthening & Not retrofitted & G \\
Angle of fabrics & CFRP & C \\
& $\pm 45^{\circ}$ & \pm 45 \\
\hline
\end{tabular}

Table 2. Mix proportions of NC and SFRC.

\begin{tabular}{|c|c|c|c|c|c|c|c|}
\hline \multirow{2}{*}{$\begin{array}{c}\text { W/C } \\
(\%)\end{array}$} & \multirow{2}{*}{$\begin{array}{l}\text { S/a } \\
(\%)\end{array}$} & \multicolumn{4}{|c|}{ Unit weight $\left(\mathrm{kg} / \mathrm{m}^{3}\right)$} & \multirow{2}{*}{ S.P. ${ }^{a)}$} & \multirow{2}{*}{$V_{f}^{\mathrm{b})}$} \\
\hline & & Water & Cement & Fine aggregate & Coarse aggregate & & \\
\hline 50 & 50.4 & 204 & 408 & 876 & 863 & $1.0 \%$ & $0.75 \%$ \\
\hline
\end{tabular}

${ }^{a}$ high range water reducing admixture to cement ratio. ${ }^{\text {b) }}$ volume fraction of steel fiber on SFRC. 
Table 3. Mix proportions of PVA FRCC.

\begin{tabular}{ccccccc}
\hline \multirow{2}{*}{$\begin{array}{c}\text { W/C } \\
(\%)\end{array}$} & \multicolumn{3}{c}{ Unit weight $\left(\mathrm{kg} / \mathrm{m}^{3}\right)$} & S.P. & M.C. ${ }^{\text {a) }}$ & $V_{f}{ }^{\text {b) }}$ \\
\cline { 2 - 5 } & Water & Cement & Silica sand & & & \\
\hline 50 & 375 & 750 & 954 & $2.0 \%$ & $0.05 \%$ & 2.0 \\
\hline
\end{tabular}

${ }^{a}$ hydroxypropyl methylcelluose to cement ratio. ${ }^{\text {b) }}$ total volume fraction of PVA fibers.

Table 4. Properties of fibers.

\begin{tabular}{lccccc}
\hline \multicolumn{2}{c}{ Fiber } & $\begin{array}{c}\text { Length } l_{f} \\
(\mathrm{~mm})\end{array}$ & $\begin{array}{c}\text { Diameter } d_{f} \\
(\mu \mathrm{m})\end{array}$ & $\begin{array}{c}\text { Tensile strength } \sigma_{f} \\
(\mathrm{MPa})\end{array}$ & $\begin{array}{c}\text { Density } \\
\left(\mathrm{g} / \mathrm{cm}^{3}\right)\end{array}$ \\
\hline \multicolumn{2}{c}{ Steel fiber } & 30 & 500 & 1196 & 7.9 \\
$\begin{array}{l}\text { PVA } \\
\text { fiber }\end{array}$ & REC15 & 12 & 40 & 1600 & 1.3 \\
\hline
\end{tabular}

Table 5. Mechanical properties of PVA FRCCs [16].

\begin{tabular}{cccccccc}
\hline \multicolumn{2}{l}{ Volume fraction of fiber, $v_{f}(\%)$} & $\begin{array}{c}f_{c u} \\
(\mathrm{MPa})\end{array}$ & $\begin{array}{c}f_{1, \mathrm{crack}} \\
(\mathrm{MPa})\end{array}$ & $\begin{array}{c}f_{u l t} \\
(\mathrm{MPa})\end{array}$ & $\begin{array}{c}f_{s p} \\
(\mathrm{MPa})\end{array}$ & $\begin{array}{c}T_{J S C E} \\
(\mathrm{kN} \cdot \mathrm{mm})\end{array}$ & $\begin{array}{c}F_{\text {JSCE }} \\
(\mathrm{MPa})\end{array}$ \\
\cline { 1 - 2 } 2.0 & $\mathrm{RF} 4000$ & 60.99 & 6.76 & 10.23 & 7.39 & 42.83 & 6.42 \\
1.9 & 0 & 53.63 & 6.61 & 10.34 & 6.63 & 47.84 & 7.18 \\
1.8 & 0.1 & 56.34 & 6.03 & 10.3 & 7.3 & 47.47 & 7.11 \\
1.7 & 0.2 & 66.93 & 6.81 & 10.65 & 6.19 & 49.85 & 7.48 \\
1.6 & 0.3 & 71.26 & 6.16 & 13.07 & 7.61 & 63.11 & 9.47 \\
1.5 & 0.4 & 67.24 & 6.64 & 8.63 & 7.14 & 33.84 & 5.08 \\
1.4 & 0.5 & 69.12 & 6.03 & 10.04 & 7.33 & 35.28 & 5.29 \\
\hline
\end{tabular}

$f_{c u}=$ compressive strength; $f_{1, \text { rrack }}=$ flexural strength at first crack; $f_{r}=$ flexural strength; $f_{s p}=$ splitting tensile strength; $T_{J S C E}=$ toughness of JSCE method; $F_{J S C E}=$ equivalent flexural strength of JSCE method.

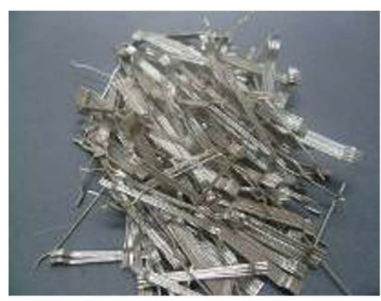

[Steel fiber]

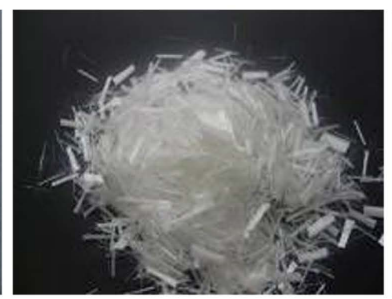

[REC15]

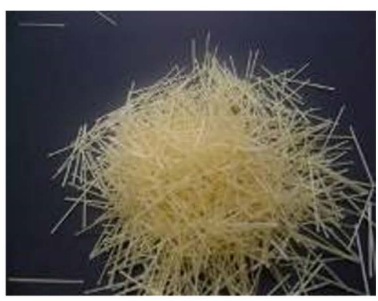

[RF4000]

Figure 2. Shapes of steel and PVA fiber.

Note that, in the mixture of Kim et al. [16], the W/C was $40 \%$, however, in this study, the W/C was modified to $50 \%$ in order to match the compressive strength of NC and SFRC.

For the measurement of flexural tensile strength, $100 \times 100 \times 400 \mathrm{~mm}$ prismatic specimens were fabricated and square specimens of $50 \times 350 \times 350 \mathrm{~mm}$ were prepared for punching test. The cast specimens were stored in water at 
$20^{\circ} \mathrm{C} \pm 3^{\circ} \mathrm{C}$ for two weeks. Fourteen days after casting, the FRPs were adhered and then cured for 14 more days at $50 \% \pm 5 \%$ relative humidity and at a temperature of $20^{\circ} \mathrm{C} \pm 3^{\circ} \mathrm{C}$. The unidirectional E-glass and high strength carbon fiber sheets were attached with epoxy resin along the shapes of punching test specimens, with a crossing at right angles of \pm 45 and 0/90 degrees. Glass fiber reinforced polymer (GFRP) was only used with the normal concrete, while the carbon fiber reinforced polymer (CFRP) was used with the three matrices. The mechanical properties of fiber sheets and resins are summarized in Table 6.

\subsection{Quasi-Static Loading Test}

The restraint conditions of punching tests are illustrated in Figure 3, the two-way punching tests were carried out with $300 \mathrm{~mm}$ clear spans, and quasi-static and impact loads were applied at the center of the specimens. The quasi-static loading with displacement control at a load rate of $0.01 \mathrm{~mm} / \mathrm{s}$ and gradually applied using a $2700 \mathrm{kN}$ capacity universal testing machine (UTM). The deflections of the center of specimens were measured with linear variable differential transformer (LVDT) [17] [18].

\subsection{Low-Velocity Impact Loading Test}

The low-velocity impact tests were carried out with a drop weight test machine that has a maximum capacity of about 800 Joules, as shown in Figure 3. The impact load and velocity were measured with the load cell in the tup and attached speedometer, respectively. When a tup passes through the hole, the speedometer measures the impact velocity, and then the computer calculates the impact energy, and displacement, etc. In this test, a $33.62 \mathrm{kgf}$ weight was dropped along a $0.7 \mathrm{~m}$ clear height, and then struck the center of the specimens. Impact velocities of weight were increased by the addition of air pressure for the tests of retrofitted concrete specimens. In the test for not reinforced specimens (NC), the average impact velocity was $4.92 \mathrm{~m} / \mathrm{sec}$. For the reinforced specimens (SFRC, PVA FRCC, and FRP retrofitted specimens), as additional air pressure applied, the impact velocities were 5.91 to $5.93 \mathrm{~m} / \mathrm{sec}$.

Table 6. Properties of FRP materials.

\begin{tabular}{|c|c|c|c|c|c|}
\hline \multirow{3}{*}{ Sheet } & & $\begin{array}{c}\text { Tensile strength } \\
\text { (MPa) }\end{array}$ & $\begin{array}{l}\text { Elastic modulus } \\
\qquad(\mathrm{GPa})\end{array}$ & $\begin{array}{c}\text { Ultimate } \\
\text { strain (\%) }\end{array}$ & $\begin{array}{c}\text { Thickness } \\
(\mathrm{mm})\end{array}$ \\
\hline & E-glass sheet & 2300 & 76 & 3.0 & 0.35 \\
\hline & $\begin{array}{l}\text { High strength } \\
\text { carbon }\end{array}$ & 4900 & 230 & 2.1 & 0.111 \\
\hline \multirow{2}{*}{ Resin } & & $\begin{array}{c}\text { Tensile strength } \\
(\mathrm{MPa})\end{array}$ & $\begin{array}{c}\text { Tensile } \\
\text { modulus (GPa) }\end{array}$ & $\begin{array}{l}\text { Ultimate } \\
\text { strain (\%) }\end{array}$ & $\begin{array}{l}\text { Density } \\
\left(\mathrm{g} / \mathrm{cm}^{3}\right)\end{array}$ \\
\hline & Epoxy & 90 & 3 & 8.0 & 1.2 \\
\hline
\end{tabular}



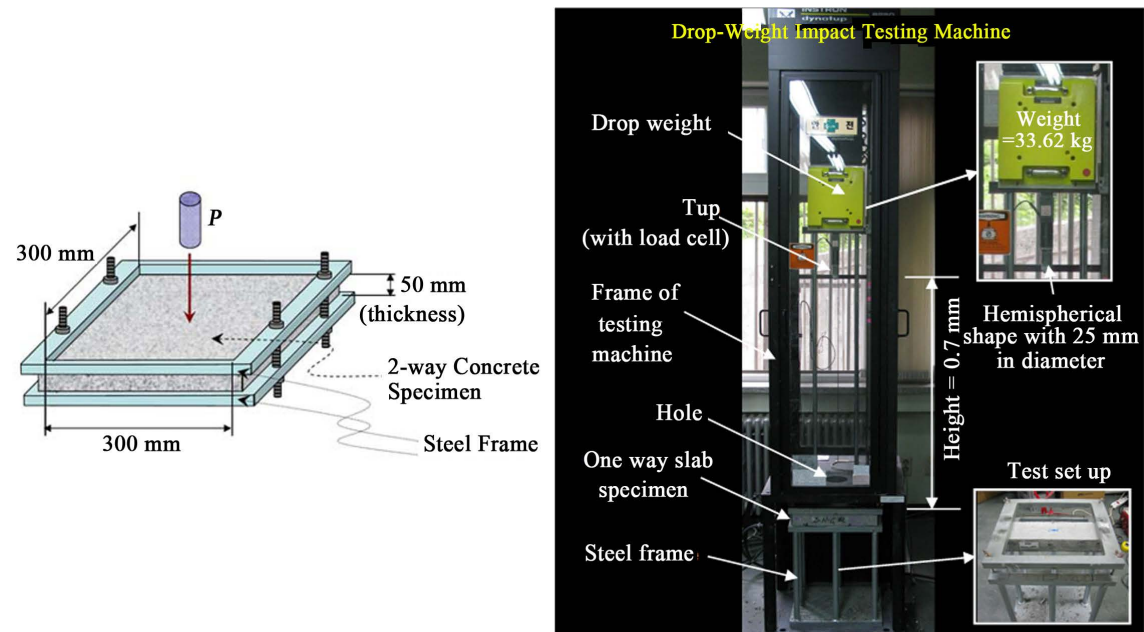

Figure 3. Test set-up of two-way punching and details of drop-weight impact testing machine.

\section{Test Results and Discussions}

\subsection{Basic Mechanical Properties of Concrete}

Tests for mechanical properties of concrete such as compressive and flexural tensile strength were carried out according to ASTM C39 and C1609. The material properties of each matrix are summarized in Table 7 and typical load-deflection curves of matrices are illustrated in Figure 4. Compressive strengths of three mixtures were about $50 \mathrm{MPa}$, similarly, however, flexural tensile strengths of SFRC and PVA FRCC were 1.4 and 2.1 times larger than flexural strength of the NC, respectively. Also, in the curve of PVA FRCC, there is a strain hardening prior to the peak load, and after the peak, the PVA FRCC shows more rapid strain softening than the SFRC's case.

\subsection{Punching Test Results}

The test results of two-way static punching tests are summarized in Table 8. Figure 5 also show the representative relationships between static loads and deflections of the two-way punching tests. As shown in Figure 5, the ultimate strength of FRP reinforced two-way NC specimens increased by 2.65 to 3.03 times greater than the plain NC series (NC-N) under quasi-static loadings, and the deflections of center at the maximum loads increased by 3.8 to 4.7 times. For the orientation of fibers, the ultimate loads and deflections of center of the 0/90 series were slightly higher than the \pm 45 series. The loads of SFRC-N specimens gradually increased, and the specimens reinforced with CFRP showed strain softening after the maximum loads.

In the case of the PVA FRCC, both the non-retrofitted specimens and reinforced specimens with CFRP after maximum loads showed strain softening. However, the peak loads of the CFRP retrofitted PVA FRCC series is not greater than that of the plain PVA FRCC specimens. The FRP retrofitted NC specimens 


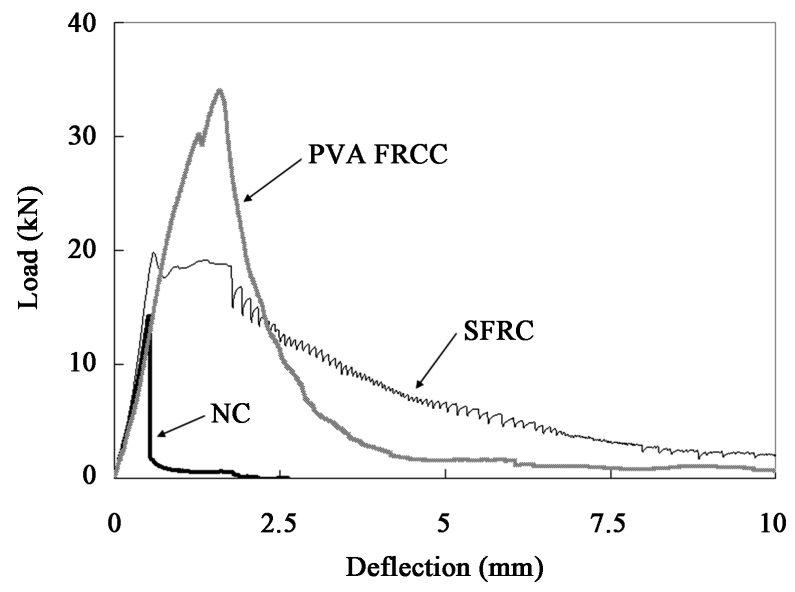

Figure 4. Typical load-deflection relationships of concrete.

Table 7. Mechanical properties of concrete.

\begin{tabular}{ccc}
\hline Materials & Compressive strength $(\mathrm{MPa})$ & Flexural strength $(\mathrm{MPa})$ \\
\hline NC & 53.20 & 4.79 \\
SFRC & 50.40 & 6.80 \\
PVA FRCC & 54.23 & 10.32 \\
\hline
\end{tabular}

Table 8. Test results of two-way static punching.

\begin{tabular}{cccc}
\hline Specimen & Maximum load $(\mathrm{kN})$ & Deflection at max load $(\mathrm{mm})$ & Dissipated energy $(\mathrm{J})$ \\
\hline N-N & 14.90 & 0.29 & 35.77 \\
N-G- \pm 45 & 43.05 & 1.14 & 45.10 \\
N-G-0/90 & 45.18 & 1.33 & 49.78 \\
N-C- \pm 45 & 39.48 & 1.11 & 45.16 \\
NC-C-0/90 & 44.66 & 1.36 & 46.11 \\
S-N & 22.24 & 5.74 & 90.58 \\
S-C- \pm 45 & 63.13 & 1.25 & 106.29 \\
P-N & 45.39 & 1.61 & 161.48 \\
P-C- $\pm 0 / 90$ & 54.21 & 0.89 & 460.82 \\
\hline
\end{tabular}

and plain SFRC specimens showed complex failure patterns of splitting and punching. In addition, in the failure cases of the splitting of concrete matrices, the deboning of FRPs were more serious. However, all the PVA FRCC series had typical punching failure as shown in Figure 5.

In the PVA FRCC series, the P-N specimens showed 4 times larger dissipated energy than for the energy of the N-N specimens. However, the CFRP retrofitted PVA FRCC specimens had similar capacities to the CFRP retrofitted SFRC elements. Also, identically to the SFRC's cases, retrofitted specimens showed a plateau at the first blow and nonlinearity of time-deflection curve, and almost failed by one blow (Figure $6 \&$ Figure 7) (Table 9). 

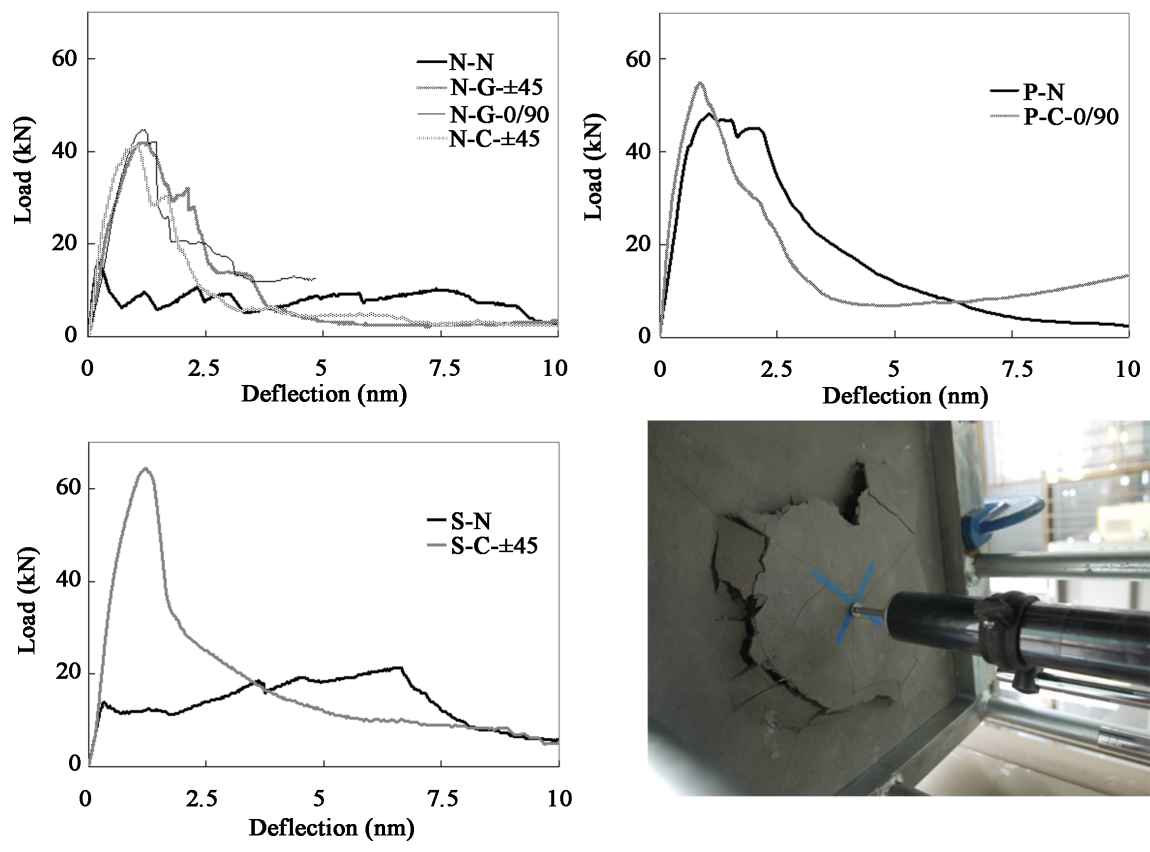

Figure 5. Load-deflection relationships of two-way punching impact tests and punching failure of PVA FRCC specimens under static load.
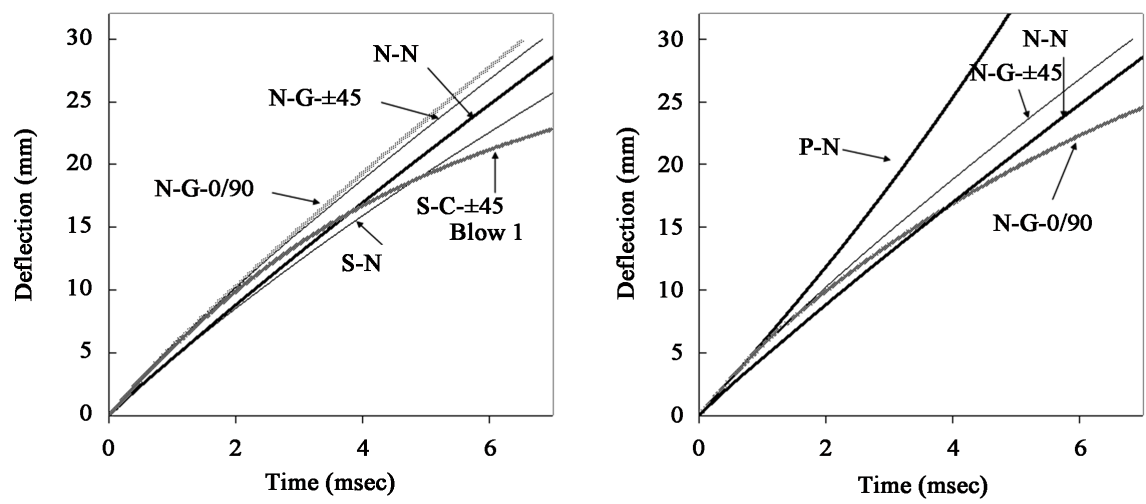

Figure 6. Time-deflection relationships of two-way punching impact test.

Table 9. Test results of two-way impact punching.

\begin{tabular}{cccc}
\hline Specimen & Maximum load (kN) & Deflection at max load (mm) & Dissipated energy (J) \\
\hline N-N & 53.23 & 2.54 & 128.08 \\
N-G-0/90 & 71.19 & 4.55 & 522.52 \\
N-C- \pm 45 & 70.30 & 3.61 & 534.07 \\
N-C-0/90 & 70.13 & 4.53 & 653.28 \\
SC-N & 63.48 & 2.09 & 405.85 \\
S-C- \pm 45 1st blow & 73.40 & 3.16 & 767.33 \\
2nd blow & 16.03 & 9.23 & 106.99 \\
P-N & 55.99 & N.A. & 543.7 \\
P-C-0/90 1st blow & 73.51 & 5.43 & 736.78 \\
2nd blow & 22.22 & 3.87 & 154.03 \\
\hline
\end{tabular}



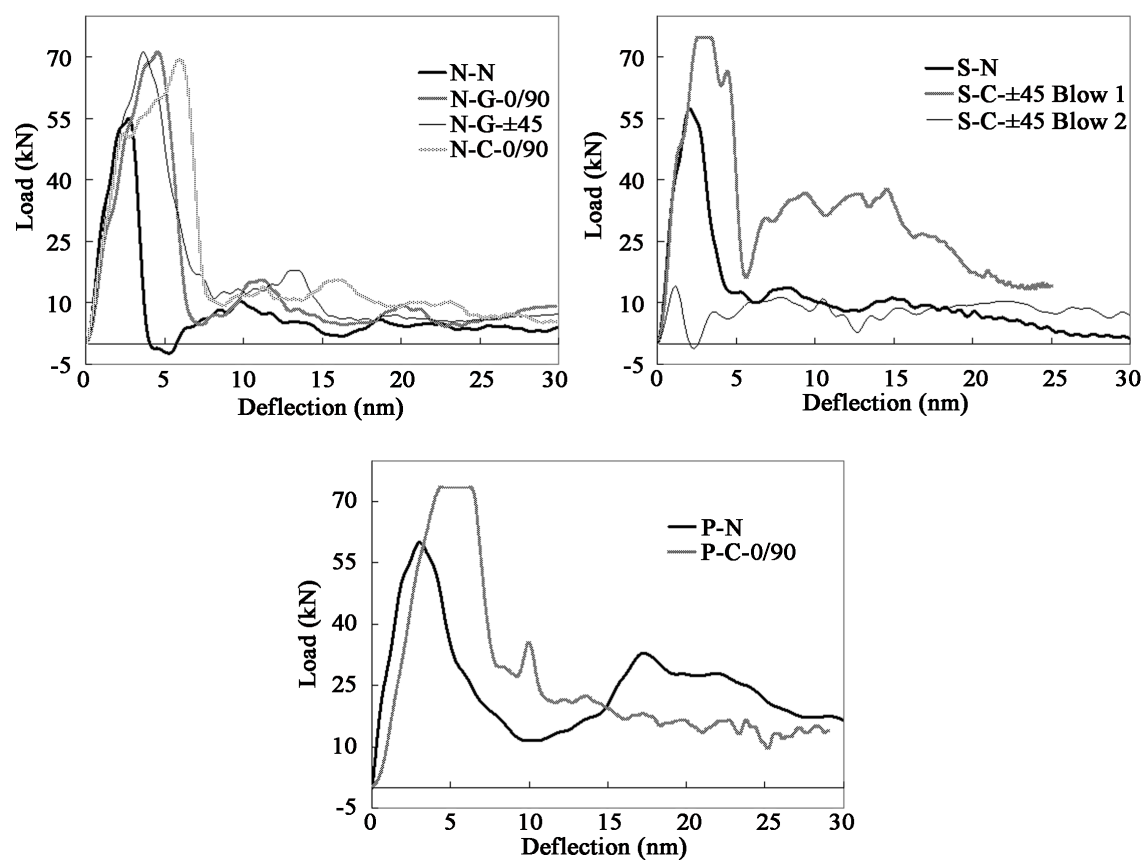

Figure 7. Load-deflection relationships of two-way punching impact tests.

Figure 8 shows representative failure patterns of the two-way specimens under impact loadings. The retrofitted specimens with FRPs or long steel fiber exhibited complex failure modes of splitting and punching. The NC specimens split with irregular fragments; however, the SFRC failed with radially splitting pieces. The FRP retrofitted SFRC showed apparent punching failures and FRPs were debonded and ruptured locally. In PVA FRCC, FRP was relatively well adhered after penetration.

\subsection{Comparison of Penetration Depth}

Kennedy (1976) [19] suggested that seven phenomena for the impact effect on concrete, as described in Figure 9. 1) Penetration: tunneling into the target by the projectile (the length of the tunnel is called the penetration depth); 2) Cone cracking and plugging: formation of a cone-like crack under the projectile and the possible subsequent punching-shear plug; 3) Spalling: ejection of target material from the proximal face of the target; 4) Radial cracking: global cracks radiating from the impact point and appearing on either the proximal or distal face of the concrete slab or both, when cracks develop through the target thickness; 5) Scabbing: ejection of fragments from the distal face of the target; 6) Perforation: complete passage of the projectile through the target with or without a residual velocity; and, 7) Overall structural responses and failures: global bending, shear and membrane responses as well as their induced failures throughout the target.

In this study, the penetration depths were assessed, and various empirical formulas of penetration depth due to missile impact are shown in Appendix. 


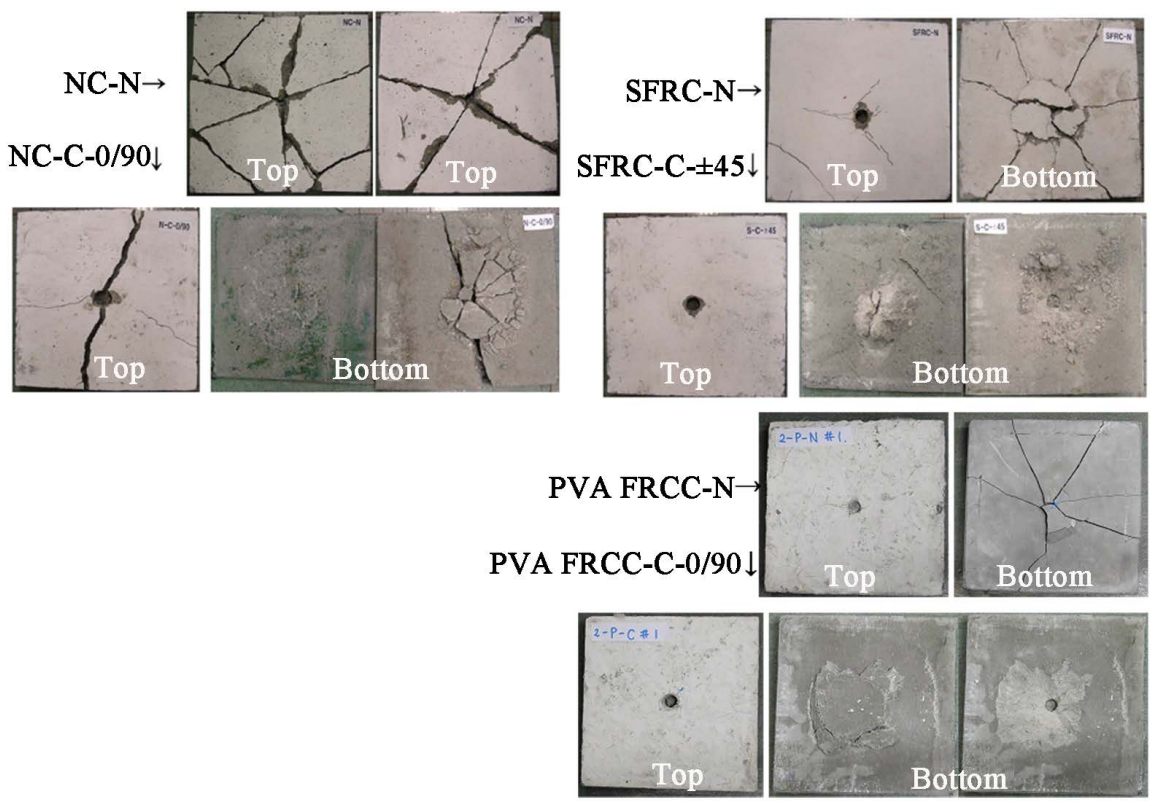

Figure 8. Representative failure patterns of two-way specimens on impact punching loads.

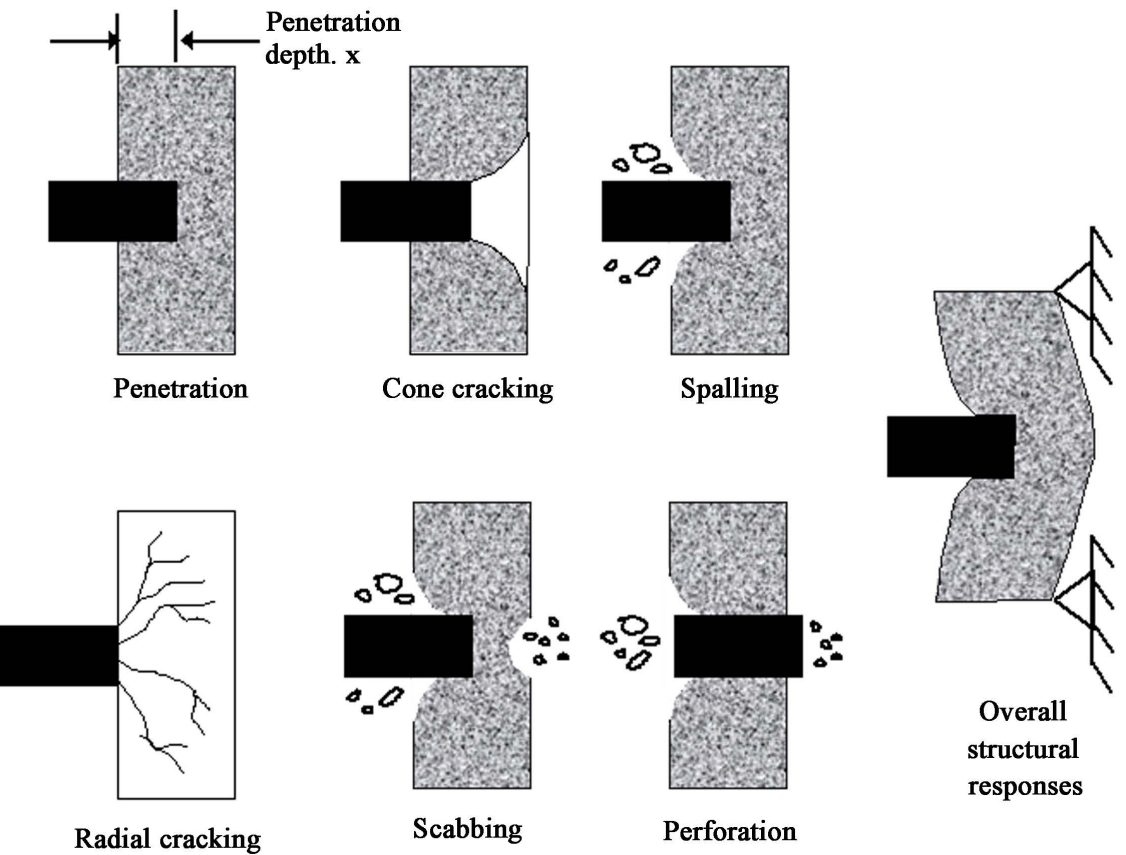

Figure 9. Missile impact effects and local damage on concrete [19] [20] [21].

The modified Petry, ACE, modified NDRC, and BRL formulae are from the tests for a lightweight and high-velocity rigid missile, whereas the Kar, Hughes, Haldar-Hamieh, and Adeli-Amin formulae are based on experiments for heavy and low-velocity impact. Formulae for perforation and scabbing [21] [22], are not considered in this study.

Table 10 is a comparison of penetration depth for experiments and empirical 
Table 10. Comparison of penetration depth.

\begin{tabular}{cccc}
\hline \multirow{2}{*}{ Formula } & \multicolumn{3}{c}{ Penetration depth $(\mathrm{mm})$} \\
\cline { 2 - 4 } & NC & SFRC & PVA FRCC \\
\hline Experiment & 36.49 & 29.55 & 27.76 \\
Modified Petry & 35.88 & 52.14 & 52.52 \\
BRL & 77.92 & 102.67 & 99.45 \\
ACE & 50.43 & 59.59 & 58.53 \\
Modified NDRC & 55.93 & 58.53 & 58.27 \\
Ammann \& Whitney & 93.59 & 134.64 & 130.64 \\
Whiffen & 186.55 & 221.26 & 235.40 \\
Kar & 55.93 & 58.53 & 58.27 \\
UKAEA & 55.93 & 58.53 & 58.27 \\
Haldar \& Hamieh & 12.30 & 19.70 & 18.34 \\
Adeli \& Amin & 12.18 & 17.30 & 16.37 \\
Hughes & 29.07 & 29.30 & 25.51 \\
Healey \& Weissman & 56.80 & 59.78 & 59.49 \\
IRS & 0.77 & 0.79 & 0.76 \\
CRIEPI & 1.00 & 1.81 & 1.34 \\
\hline
\end{tabular}

formulae. The given conditions are: the weight and tup are steel (hence, $\mathrm{E}=2.00$ $\times 10^{9} \mathrm{~Pa}$ ), the mass of the projectile is $33.62 \mathrm{~kg}$, the diameter of the projectile is $25 \mathrm{~mm}$, and the aggregate diameter is $20 \mathrm{~mm}$. The compressive and tensile strength used are the values of Table 9. Also, the measured projectile impacting velocities are 4.912, 5.923, and $5.944 \mathrm{~m} / \mathrm{s}$ for NC, SFRC, and PVA FRCC, respectively. Except the modified Petry [19] [23] [24] and Hughes formulae [25], all other formulae use the compressive strength of concrete, while only the Hughes formula uses the tensile strength of concrete. Therefore, with the exception of the Hughes formula, all other formulae that governed by the missile velocity predict similar values for plain and fiber reinforced concrete, or higher penetration depth in fiber reinforced concrete than in the NC.

As can be seen in Table 10, the Hughes formula is well predicted for the fiber reinforced concretes. For the NC specimen, since the tensile strength is much higher than typical values, i.e. the prediction equations for modulus of rupture of concrete $\left(f_{r}=0.63 \sqrt{f_{c}^{\prime}}=4.4 \mathrm{MPa}\right.$ in this test), the Hughes formula seems to show an underestimated value. However, as shown in Figure 10, since the NC specimens were split under impact loading, displacements of the end of the tup can be overestimated. Therefore, for the plain concrete, the missile effects should be adequately assessed by specimens of large dimensions. The solid lines in Figure 10 show tendencies of the Hughes formula for $V_{0}=4.9$ and $5.9 \mathrm{~m} / \mathrm{s}$, also lozenge shaped dots means the average perforation depth of each matrix. 


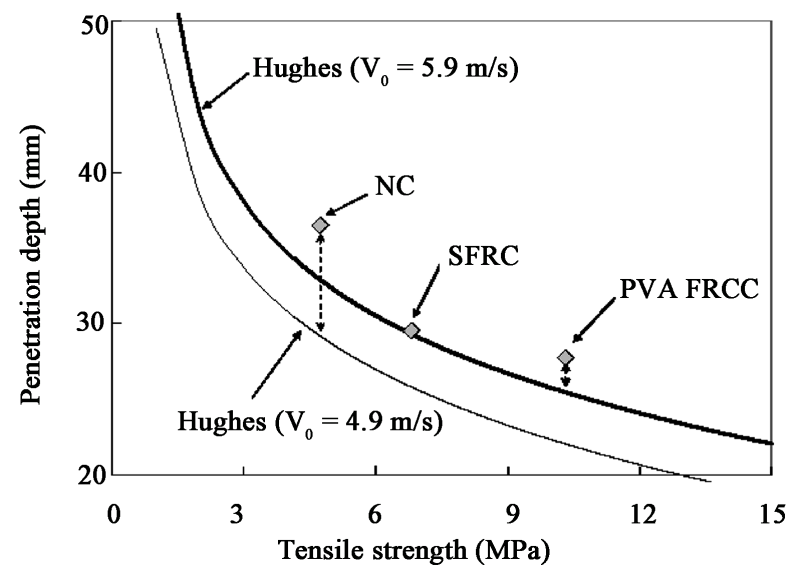

Figure 10. Comparison of penetration depth between experiment and Hughes formula.

\section{Concluding Remarks}

Punching tests were performed in order to observe the behaviors of fiber reinforced polymer (FRP) strengthened and fiber reinforced concrete specimens for quasi-static and low-velocity impact loads by using the universal testing machine (UTM) and drop weight testing machine. The following is an outline of concluding remarks for the material tests:

1) Two-way square specimens were fabricated with normal concrete (NC), steel fiber reinforced concrete (SFRC), and hybrid PVA fiber reinforced cementitious composite (PVA FRCC). For the hybrid PVA FRCC, two different types of fiber were used, and the FRPs were attached along the shapes of the specimens at \pm 45 and $0 / 90$ degrees.

2) The maximum load of FRP reinforced NC specimens increased by 2.65 to 3.03 times greater than the plain NC series under quasi-static loadings, and the deflections of center at the maximum loads increased by 3.8 to 4.7 times. The ultimate loads of the SFRC-N series increased by $38 \%$ more than the N-N series, and for the PVA FRCC, the carbon fiber reinforced polymer (CFRP) strengthening improves $62 \%$ of the peak load. The loads of SFRC-N specimens gradually increased, but the specimens reinforced with CFRP showed strain softening after the maximum loads. Both the non-retrofitted specimens and reinforced PVA FRCC specimens with CFRP after maximum loads exhibited strain softening.

3) The FRP reinforced NC, SFRC, and PVA FRCC specimens showed twice the amount of enhanced dissipated energy (total energy) under impact loadings than the non-retrofitted specimens. In the low-velocity impact test of the two-way NC specimens strengthened by FRPs, the ultimate impact loads increased by 1.33 times, and the total dissipated energy increased by 4 to 5 times greater than the plain NC series. For the two-way specimens, the total energy increased by $217 \%$ between the non-retrofitted SFRC and NC specimens. The total dissipated energy of the CFRP retrofitted SFRC was twice greater than that 
of the plain SFRC series. In the PVA FRCC series, the P-N specimens showed 4 times greater dissipated energy than for the energy of the N-N specimens. However, the CFRP retrofitted PVA FRCC specimens had similar capacities to the CFRP retrofitted SFRC elements.

4) For the penetration of two-way specimens with steel fiber, the Hughes formula considering the tensile strength of concrete was a better predictor than other empirical formulae. However, for plain concrete, specimens need to be of larger size to avoid splitting failure. In addition, penetration depth due to missile impact may be much different due to the tensile strength of fiber reinforced concrete, so it should be improved through various experiments.

\section{References}

[1] Bindiganavile, V., Banthia, N. and Aarup, B. (2002) Impact Response of U1tra-High-Strength Fiber-Reinforced Cement Composite. ACI Material Journal, 99, 543-548.

[2] Rao, H.S., Ghorpade, V.G., Ramana, N.V. and Gnanwswar, K. (2010) Response of SIFCON Two-Way Slabs under Impact Loading. International Journal of Impact Engineering, 37, 452-458. https://doi.org/10.1016/j.ijimpeng.2009.06.003

[3] Sukontajukkul, P., Mindess, S., Banthia, N. and Mikami, T. (2001) Impact Resistance of Laterally Confined Fibre Reinforced Concrete Plates. Material and Structures, 34, 612-618. https://doi.org/10.1007/BF02482128

[4] Habel, K. and Gauvreau, P. (2008) Response of Ultra-High Performance Fiber Reinforced Concrete (UHPFRC) to Impact and Static Loading. Cement and Concrete Composite, 30, 938-946. https://doi.org/10.1016/j.cemconcomp.2008.09.001

[5] Li, V.C. (2005) Engineered Cementitious Composites. Proceedings of the 3rd International Conference on Construction Materials, D-documents/1-05-SS-GF01_FP.pdf, 22-24August, 2005, Vancouver, Canada.

[6] Min, K.H., Cho, S.H., Kim, Y.W., Shin, H.O. and Yoon, Y.S. (2009) Assessment on Impact Resisting Performance of HPFRCCs Using Hybrid PVA Fibers. Proceedings of the 2 nd International Workshop on Performance, Protection \& Strengthening of Structures under Extreme Loading, 19-21 August 2009, Hayama, Japan.

[7] Min, K.H., Kim, Y.W., Yang, J.M., Lee, J.S. and Yoon, Y.S. (2009) Enhancing the Flexural Performance of Hybrid HPFRCC. Proceedings of the 4th International Conference on Construction Materials. Performance, Innovations and Structural Implications, August 24-26, 2009, Nagoya, Japan.

[8] Buchan, P.A. and Chen, J.F. (2007) Blast Resistance of FRP Composites and Polymer Strengthened Concrete and Masonry Structures-A State-of-The-Art Review. Composite Part B: Engineering, 38, 509-522. https://doi.org/10.1016/j.compositesb.2006.07.009

[9] Chen, C.C. and Li, C.Y. (2005) Punching Shear Strength of Reinforced Concrete Slabs Strengthened with Glass Fiber Reinforced Polymer Laminates. ACI Structural Journal, 102, 535-542.

[10] Malvar, L.J., Crawford, J.E. and Morrill, K.B. (2007) Use of Composites to Resist Blast. Journal of Composite for Construction, 11, 601-610. https://doi.org/10.1061/(ASCE)1090-0268(2007)11:6(601)

[11] Silva, P.F. and Lu, B. (2007) Improving the Blast Resistance Capacity of RC Slabs with Innovative Composite Materials. Composite Part B: Engineering, 38, 523-534. 
https://doi.org/10.1016/j.compositesb.2006.06.015

[12] ACI Committee 440 (2002) Guide for the Design and Construction of Externally Bonded FRP Systems for Strengthening Concrete Structures, ACI 440.2R-02. American Concrete Institute, MI, USA.

[13] Bank, L.C. (2006) Composites for Construction: Structural Design with FRP Materials. John Wiley \& Sons, NJ, USA, 214-271. https://doi.org/10.1002/9780470121429

[14] Teng, J.G., Chen, J.F., Smith, S.T. and Lam, L. (2002) FRP-Strengthened RC Structures. John Wiley \& Sons, West Sussex, UK, 31-46.

[15] Kim, Y.W. (2008) Enhancing the Structural Behavior of High-Performance Fiber Reinforced Cementitious Composites Using Hybrid PVA Fibers. M.Sc. Thesis, Korea University, South Korea.

[16] Kim, Y.W., Min, K.H., Yang, J.M. and Yoon, Y.S. (2008) Flexural and Impact Resisting Performance of HPFRCCs using Hybrid PVA Fibers. Journal of the Korea Concrete Institute, 21, 705-712. (In Korean) https://doi.org/10.4334/JKCI.2009.21.6.705

[17] Min, K.H., Yang, J.M., Yoo, D.Y. and Yoon, Y.S. (2010) Flexural and Punching Performances of FRP and Fiber Reinforced Concrete in Impact Loading. Proceedings of the 5 th International Conference on FRP Composites in Civil Engineering, Beijing, 27-29 September 2010, 410-414.

[18] Min, K.H., Shin, H.O., Yoo, D.Y. and Yoon, Y.S. (2011) Flexural and Punching Behaviors of Concrete Strengthening with FRP Sheets and Steel Fibers under Low-Velocity Impact Loading. Journal of the Korea Concrete Institute, 23, 31-38. (In Korean) https://doi.org/10.4334/JKCI.2011.23.1.031

[19] Kennedy, R.P. (1976) A Review of Procedures for the Analysis and Design of Concrete Structures to Resist Missile Impact Effects. Nuclear Engineering and Design, 37, 183-203. https://doi.org/10.1016/0029-5493(76)90015-7

[20] Berriaud, C., Sokolovsky, A., Gueraud, R., Dulac, J. and Labrot, R. (1978) Local Behaviour of Reinforced Concrete Walls under Missile Impact. Nuclear Engineering and Design, 45, 457-469. https://doi.org/10.1016/0029-5493(78)90235-2

[21] Li, Q.M., Reid, S.R., Wen, H.M. and Telford, A.R. (2005) Local Impact Effects of Hard Missiles on Concrete Targets. International Journal of Impact Engineering, 32, 224-284. https://doi.org/10.1016/j.ijimpeng.2005.04.005

[22] Chung, C.H., Choi, H., Lee, J.W. and Choi, K.R. (2010) Evaluation of Local Effect Prediction Formulas for RC Slabs Subjected to Impact Loading. Journal of Korean Civil Engineering Society, 30, 543-560. (In Korean)

[23] Samuely, F.J. and Hamann, C.W. (1939) Civil Protection. The Architectural Press, Princeton.

[24] Amirikian, A. (1950) Design of Protective Structures (A New Concept of Structural Behavior). Report NT-3726, Bureau of Yards and Docks, Department of the Navy.

[25] Hughes, G. (1984) Hard Missile Impact on Reinforced Concrete. Nuclear Engineering and Design, 77, 23-35. https://doi.org/10.1016/0029-5493(84)90058-X

[26] Gwaltney, R.C. (1968) Missile Generation and Protection in Light-Water-Cooled Power Reactor Plants. ORNL NSIC-22, Oak Ridge National Laboratory, Oak Ridge.

[27] Adeli, H. and Amin, A.M. (1985) Local Effects of Impactors on Concrete Structures. Nuclear Engineering and Design, 88, 301-317. https://doi.org/10.1016/0029-5493(85)90165-7

[28] Bangash, M.Y.H. (1989) Concrete and Concrete Structures: Numerical Modelling 
and Application. Elsevier Applied Science, London.

[29] Chelapati, C.V., Kennedy, R.P. and Wall, I.B. (1972) Probabilistic Assessment of Aircraft Hazard for Nuclear Power Plants. Nuclear Engineering and Design, 19, 333-364. https://doi.org/10.1016/0029-5493(72)90136-7

[30] ACE (1946) Fundamentals of Protective Design. Report AT120 AT1207821, Army Corps of Engineers, Office of the Chief of Engineers.

[31] Kennedy, R.P. (1966) Effects of an Aircraft Crash into a Concrete Reactor Containment Building. Holmes \& Narver Inc., Anaheim.

[32] NDRC (1946) Effects of Impact and Explosion. Summary Technical Report of Division 2, Vol. 1, National Defense Research Committee, Washington DC.

[33] Whiffen, P. (1943) UK Road Research Laboratory. Note No. MOS/311.

[34] Kar, A.K. (1978) Local Effects of Tornado-Generated Missiles. Journal of the Structural Division, 104, 809-816.

[35] Barr, P. (1990) Guidelines for the Design and Assessment of Concrete Structures Subjected to Impact. Report, UK Atomic Energy Authority, Safety and Reliability Directorate, HMSO, London.

[36] Haldar, A. and Hamieh, H. (1984) Local Effect of Solid Missiles on Concrete Structures. Journal of Structural Engineering, 110, 948-960. https://doi.org/10.1061/(ASCE)0733-9445(1984)110:5(948)

[37] Haldar, A. (1985) Energy-Balanced Approach to Evaluation Local Effects of Impact of Nondeformable Missiles on Concrete Structures. Transactions of the International Conference on Structural Mechanics in Reactor Technology, J, 203-214.

[38] Bangash, M.Y.H. (1993) Impact and Explosion: Structural Analysis and Design. CRC Press, Boca Raton.

[39] Kojima, I. (1991) An Experimental Study on Local Behaviour of Reinforced Concrete Slabs to Missile Impact. Nuclear Engineering and Design, 130, 121-132. https://doi.org/10.1016/0029-5493(91)90121-W 


\section{Appendix: Empirical Formulae for Penetration Depth}

\section{Modified Petry formula [19] [23] [24]}

$$
x=k \frac{M}{d^{3}} \log _{10}\left(1+\frac{V_{0}^{2}}{19,974}\right)
$$

where, $k=6.36 \times 10^{-4}$ for massive plain concrete;

$$
\begin{aligned}
& =3.39 \times 10^{-4} \text { for normal reinforced concrete; and } \\
& =2.26 \times 10^{-4} \text { for specially reinforced concrete in modification Petry I. }
\end{aligned}
$$

Ballistic Research Laboratory (BRL) formula [19] [26] [27] [28]

$$
\frac{x}{d}=\frac{1.33 \times 10^{-3}}{\sqrt{f_{c}^{\prime}}}\left(\frac{M}{d_{3}}\right) d^{0.2} V_{0}^{1.33}
$$

Army corps of engineers (ACE) formula [19] [29] [30]

$$
\frac{x}{d}=\frac{3.5 \times 10^{-4}}{\sqrt{f_{c}^{\prime}}}\left(\frac{M}{d^{3}}\right) d^{0.215} V_{0}^{1.5}+0.5
$$

Modified NDRC formula [19] [31] [32]

$$
\begin{aligned}
& x / d=2 G^{0.5} \text { for } G \geq 1 \\
& x / d=G+1 \text { for } G<1 \\
& G=3.8 \times 10^{-5} \frac{N^{*} M}{d \sqrt{f_{c}^{\prime}}}\left(\frac{V_{0}}{d}\right)^{1.8}
\end{aligned}
$$

Ammann and Whitney formula [19]

$$
\frac{x}{d}=\frac{6 \times 10^{-4}}{\sqrt{f_{c}^{\prime}}} N^{*}\left(\frac{M}{d^{3}}\right) d^{0.2} V_{0}^{1.8}
$$

Whiffen formula [33]

$$
\frac{x}{d}=\left(\frac{2.61}{\sqrt{f_{c}^{\prime}}}\right)\left(\frac{M}{d^{3}}\right)\left(\frac{d}{a}\right)^{0.1}\left(\frac{V}{533.4}\right)^{n}
$$

where, $n=97.51 /\left(f_{c}^{\prime}\right)^{0.25}$, and about $\pm 15 \%$ prediction accuracy, the corresponding ranges of application are $5.52<f_{c}^{\prime}<68.95 \mathrm{MPa}, 0.136<M<9979.2$ $\mathrm{kg}, 12.7<d<965.2 \mathrm{~mm}$, and $0<V_{0}<11.27 .8 \mathrm{~m} / \mathrm{s}$.

Kar formula [28] [34]

$$
\begin{aligned}
& x / d=2 G^{0.5} \text { for } G \geq 1 \\
& x / d=G+1 \text { for } G<1 \\
& G=3.8 \times 10^{-5}\left(\frac{E}{E_{s}}\right)^{1.25} \frac{N^{*} M}{d \sqrt{f_{c}^{\prime}}}\left(\frac{V_{0}}{d}\right)^{1.8}
\end{aligned}
$$

where, $E, E_{s}=$ elastic moduli of the projectile and steel, respectively. If the projectile is steel, formula is identical to the modified NDRC formula.

UKAEA formula [35]

$$
x / d=0.275-[0.0756-G]^{0.5} \text { for } G \leq 0.0726
$$




$$
\begin{aligned}
& x / d=[4 G-0.242]^{0.5} \text { for } 0.0726<G \leq 1.065 \\
& x / d=G+0.9395 \text { for } G>1.065 \\
& G=3.8 \times 10^{-5} \frac{N^{*} M}{d \sqrt{f_{c}^{\prime}}}\left(\frac{V_{0}}{d}\right)^{1.8}
\end{aligned}
$$

Within $25<V_{0}<300 \mathrm{~m} / \mathrm{s}, 22<f_{c}^{\prime}<44 \mathrm{MPa}$, and $500<M / d^{\beta}<200,000$ $\mathrm{kg} / \mathrm{m}^{3}$, the prediction accuracy is $\pm 20 \%$ for $x / d>0.75$, and $+100 \%$ to $-50 \%$ for $x / d<0.75$.

Haldar-Hamieh formula [36] [37]

$$
\begin{aligned}
& x / d=-0.0308+0.2251 I_{a} \text { for } 0.3 \leq I_{a} \leq 4.0 \\
& x / d=0.6740+0.0567 I_{a} \text { for } 4.0<I_{a} \leq 21.0 \\
& x / d=1.1875+0.0299 I_{a} \text { for } 21.0<I_{a} \leq 455 \\
& I_{a}=\frac{M N^{*} V_{0}^{2}}{d^{3} f_{c}^{\prime}} ; \text { suggested impact factor }
\end{aligned}
$$

Adeli-Amin formula [27]

$$
\begin{aligned}
& x / d=0.0416+0.1698 I_{a}-0.0045 I_{a}^{2} \text { for } 0.3 \leq I_{a} \leq 4.0 \\
& x / d=0.0123+0.196 I_{a}-0.008 I_{a}^{2}+0.0001 I_{a}^{3} \text { for } 4.0<I_{a} \leq 21.0
\end{aligned}
$$

Hughes formula [25]

$$
\begin{aligned}
\frac{x}{d} & =0.19 \frac{N_{h} I_{h}}{S} \\
I_{h} & =\frac{M V_{0}^{2}}{d^{3} f_{t}} \\
S & =1.0+12.3 \ln \left(1.0+0.03 I_{h}\right)
\end{aligned}
$$

Healey and Weissman formula [28]

$$
\begin{aligned}
& x / d=2 G^{0.5} \text { for } G \geq 1 \\
& x / d=G+1 \text { for } G<1 \\
& G=4.36 \times 10^{-5}\left(\frac{E}{E_{s}}\right) \frac{N^{*} M}{d \sqrt{f_{c}^{\prime}}}\left(\frac{V_{0}}{d}\right)^{1.8}
\end{aligned}
$$

IRS formula [38]

For penetration

$$
x=3703.376\left(f_{c}^{\prime}\right)^{-0.5}+1673\left(f_{c}^{\prime}\right)^{-0.18} \exp \left[-0.104\left(f_{c}^{\prime}\right)^{0.18}\right]
$$

For total protection of the penetration, perforation, and scabbing, the minimum wall thickness is

$$
\begin{aligned}
& \operatorname{SVOLL}=3913.119\left(f_{c}^{\prime}\right)-0.5+132.409\left(f_{c}^{\prime}\right)^{-0.18} \exp \left[-0.104\left(f_{c}^{\prime}\right)^{0.18}\right] \\
& \text { CRIEPI formula [39] } \\
& \frac{x}{d}=\frac{0.0265 N^{*} M d^{0.2} V_{0}^{2}\left(114-6.83 \times 10^{-4} f_{c}^{2 / 3}\right)}{f_{c}^{2 / 3}} \times\left[\frac{\left(d+1.25 H_{r}\right) H_{r}}{\left(d+1.25 H_{0}\right) H_{0}}\right]
\end{aligned}
$$




\section{Notation}

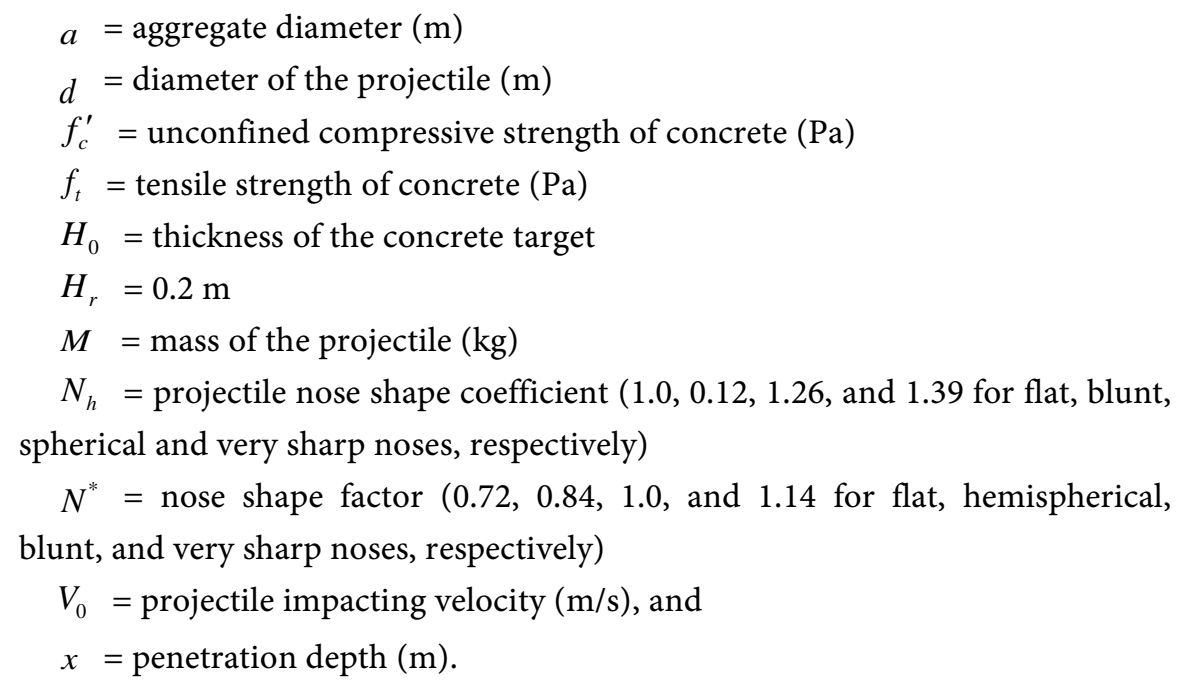

